\title{
UNDERSTANDING THE DEMAND SIDE AND COORDINATING THE SUPPLY SIDE FOR CONNECTED GOODS AND SERVICES
}

\author{
Gro Ladegård \& Eirik Romstad \\ Department of Economics and Resource Management, Norwegian University of Life Sciences \\ http://www.umb.no gro.ladegard@umb.noeirik.romstad@umb.no
}

\begin{abstract}
This paper addresses the coordination and innovation issues needed for promoting value added at the rural and regional level. There are two sides to value added: the ability to meet consumer demand, and to identify least cost ways of supplying the demanded goods. Human and social capital plays an important role on both sides.

At the municipality level the supply side issues are complex. First, because the production space has far more dimensions than for the single entrepreneur. Second, because the value of some goods and services produced depend on what other goods and services that is available. On the supply side networks are important to solve the coordination issues, while networks for identifying and understanding consumer preferences are important on the demand side. Participation in these two network types compete for the same scarce resource, the time of the inhabitants of a municipality.

We address these issues in more detail. A major insight from our work is that in addition to the time conflict, innovation and new information may make it more difficult to maintain coordination networks.
\end{abstract}

Key words: regional development, multifunctionality, municipalities, demand, coordination, networks

\section{Introduction}

This paper deals with how competitiveness and welfare can be enhanced at the municipality or regional level. ${ }^{1}$ To be competitive is to deliver demanded goods and services at prices that attract customers. That requires understanding both the demand and supply side of an economy. At the community, municipality or regional level the opportunity set is far larger than for an individual producer for several reasons. First, the amount of skills and knowledge among a collection of producers is far larger than for a single producer. Second, the variety of resources is higher. This implies that the production possibility set spans more dimensions at the community level than what is the case for a single producer. However, while the supply side opportunities are larger, there are also some challenges. Before moving to these, we will have a closer look at the demand side - a much neglected issue in rural (and regional) development.

Our stratified Google search on "rural development" with the exact phrase "demand analysis" only produced one peer reviewed article published after 2000, namely Getz and Brown (2004). In their paper on the demand for wine tourism they report that long distance traveling wine tourists look for wine growing areas that also are known for scenic beauty and offer a multitude of leisure activities. We think this emphasis on multiple options is not unique to wine tourists as our little tale below illustrates.

Imagine a family of four consisting of two adults and two children on vacation by car. For simplicity and without loss of generality let us call them Hansen. After having been stuck together in the same car for three to four hours with the exception of some short breaks, they start to be pretty fed up with each other, and now they are looking for a good place to stop and have a break from each other. As many modern households the Hansens have diverse interests. They are therefore more likely to stop on a place that offers activities that cater to their diverse demands. Mr. Hansen dreams about two to three hours of peaceful fly fishing, while Mrs. Hansen is looking for a place with art galleries and antique shops. The children, one boy and one girl, also have different wants. The teenage son looks for a place where he could play some sports, like a friendly pick-up game of soccer or basketball, while the daughter wants to go horseback riding. Now suppose they found some place that in a credible way offered these activities in a safe environment, i.e., it is possible to let

\footnotetext{
${ }^{1}$ For the rest of this paper, the terms community level, municipality level and regional level will be used interchangeably.
} 
the children loose. It is far more likely that they would stop at such a place rather than at a place which has less to offer. If the Hansens were well organized and structured, they would most likely have sought such locations out on the web before starting on their journey. ${ }^{2}$

After two to three hours of being apart the Hansens reconvene. Hopefully, all are rested and ready to enjoy being together again. If they enjoyed their activities, it is not unlikely that they would like to repeat the activities the morning after. They would then be looking for a place to have a nice dinner, and maybe spend the night in the vicinity. This is, were the "big money" are spent, i.e., some local businesses are really going to make a profit. However, the profits enjoyed by the restaurant and lodging providers are not only a result of their actions. After all, the Hansens may not have stopped if it had not been for the fly fishing, the art galleries and antique shops, the local sports facility where some other children were playing pickup games, and the riding center.

While too many regional and rural development strategies focus mainly on the supply side, we think social welfare is further enhanced if one is able to see supply and demand together. This holds for the local business benefits and consumer satisfaction. In our tourism tale it is easy to see that it is the municipality's ability to meet consumer demands that determine the level of success of the businesses. This ability increases if there is cooperation among the local businesses in terms of marketing, in particular with increased use of the web for planning tourist activities. But marketing is one thing, being able to meet the demand is another issue.

Some interesting and complicated issues quickly arise in our setting. Suppose that some of the activities that made the Hansens stop, for example the art gallery, were not profitable by themselves. Could the local restaurants and lodging facilities increase their profits by offering some side payments to non-profitable activities that increase the chances someone will choose to have dinner and spend the night?

We will therefore look at various ways at which local businesses may become more able to meet the demand challenges. While the relevance of our perspective is most easily seen for activities related to tourism, we think the potential of coordinated action and networks go beyond the tourism sector. Networks can be separated in two main purposes: (i) coordination, and (ii) exploration and innovation. These two network classes differ substantially in their basic characteristics, but have one common feature - they both compete for the entrepreneur's time together with the time allotted to run the business. Here, it should be noted that these two roles already are recognized in the rural development literature (see for example Léon 2005).

Section 2 looks at the supply side when multiple products are produced, while Section 3 analyzes the coordination issues using some stylized models. In Section 4 we look at networks as one way of resolving the coordination issues before Section 5 concludes.

\section{Multi-product production at the regional level}

This section starts with multi-product production at the firm level using a multifunctionnality approach that is quite well known in agriculture. We then extend the firm level analysis to the municipality level, before we summarize the supply side issues, and look at interactions with the demand side.

\subsection{Multifunctionality as we (ought to) know it}

Romstad (2008) argues that multifunctionality basically is multiproduct production for a given resource or cost base, $C$. This is a very standard approach in production economics that is described in several books (see for example Debertin 1986; Chambers 1988). This gives the familiar production possibility set, where optimal allocation implies that the rate of product transformation equals the negative slope of relative price line, i.e.,

$$
R P T_{y z}=-\frac{p_{y}}{p_{z}}
$$

Figure 1 provides a graphical illustration.

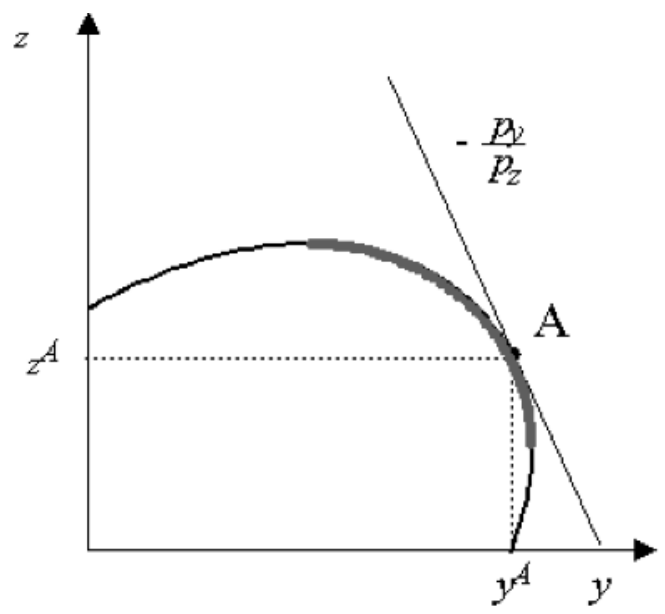

Figure 1: The production possibility frontier and the optimal allocation

Note that all joint pairs $(y, z)$ on the production possibility frontier (the product transformation curve) can be achieved with the same costs, $C$. For positive prices on $y$ and $z$ the profit maximizing allocations must then be located on the thick portion of the production possibility frontier. ${ }^{3}$ It follows from [1] that prices provide information to producers on how much to produce of each commodity.

\footnotetext{
2 Please accept our apologies for the stereotypes this imaginary family portrays. Our main point is to illustrate that modern families are diverse in their demands, and that even on vacations, they would like to be able to pursue some of their individual interests.

3 While this brief analysis assumes revenue maximization for a given costs, it is easy to see that allocating production resources so that [1] holds makes it easier for any producer to avoid running a deficit.
} 
Following Romstad (2008) we briefly turn to production in the longer run. Suppose that due to changes in consumer preferences the relative price between $y$ and $z$ changes so that $p_{y} / p_{z}$ decreases, i.e., it becomes more profitable to produce $z$ at the expense of $y$. Moreover, assume that this relative price change is expected to last (for some time). This could trigger innovation that changes the production possibility set. Let the new price change be given by , $a p_{y} / b p_{z}$ where $a<1$ and $\left.b\right\rangle$ 1. Figure 2 provides an illustration.

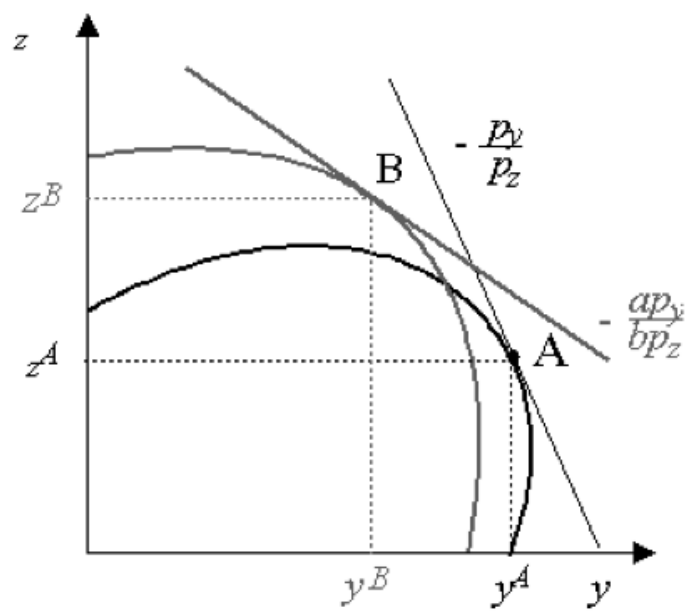

Figure 2: Perceived changes in the shape of the production possibility set from a perceived long term price change.

The perceived changes in the production possibility set in Figure 2 do not happen instantaneously. Replacing old technology with the new is a gradual process. Johansen (1972) refers to this gradual adoption of new technologies as the putty-clay model of production. That is, as production possibility sets change over time, they are "pulled" by what appears to be the relevant price changes.

An entrepreneur who is concerned about maximizing his expected profits will consider various options and allocate his or her resources, including time, so that the marginal value of each input used in the production process is equal at the margin (the last unit produced). The extent (size) of the operation will be determined by constrained resources (like available land of suitable quality), and the size of production possibility set.

\subsection{Multifunctionality at the community level}

Multiproduct production at the community level follows the basic same economic principles as for the entrepreneur, but there are some notable additions. For one, the availability of resources (including time) increases significantly. Second, the number of options, i.e., the dimensions of the production possibility set increases. Figure 3 provides an illustration of an expansion from Figure 1 by adding a third dimension, $w$.

When the production possibility set from Figure 1 is expanded with one more dimension, $w$, the optimal allocation of $y$ and $z$ may also change. Figure 1 can basically be seen as one of the curves in Figure 3 where $w$ is fixed at some level, $w$, usually zero. As $w$ is increased revenues also

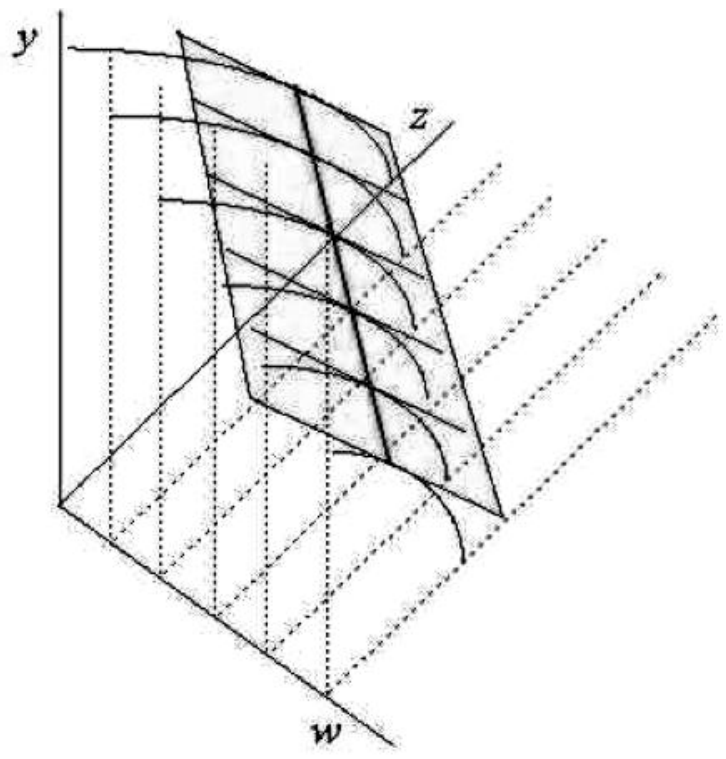

Figure 3: The impact of optimal allocation of adding products.

grow, but the strain on available resources that previously were allocated to only two products also increase. The optimal allocation in this case is now determined by the tangency of the (yellow) plane in $y z w$ space to the frontier of the three dimensional production possibility set.

At the municipality level the number of dimensions will be much larger, but the same basic principles apply, i.e., in optimum marginal costs for all inputs are the same evaluated at the chosen allocation, which again are equated with the marginal revenues (the prices in the case that the producers in the municipality produces so little of the chosen products that market prices are not affected). A notable feature in this connection is that as the product range changes, so could the expected payoffs of the other products.

The possible high number of products offered at the municipality level makes the production decision far more complicated than for the single entrepreneur, in particular if we look back at our starting example with the Hansens. An additional complicating with the Hansen example is that the prices that some producers may be able to charge varies depending on what other products that are available. Going back to the basic exposition surrounding Figure 3, this implies that the hyperplane may not be linear, but curved. Another feature is the need for coordinated action as recognized in several works on rural development (see for example van Huylenbroeck Durand 2003; Kydd and Dorward 2004).

\section{The coordination problem}

Coordination problems take many different forms. In the rural (and regional) development literature it is well recognized. A typical example is the impact of infrastructure on the viability of businesses. In our setting the coordination problem takes a different form - the actions of some producers 
may cause positive or negative externalities on other producers (see for example Baumol and Oates 1988 for an overview).

There are several ways of correcting externalities pending what kind they are. The standard economics approach is that some central agency introduces a set of taxes or tradable permits that create a price on the externalities (Baumol and Oates ibid.). Others, with Ostrom $(1990,1995)^{4}$ being the most known proponent for this view, argue that agents are able to self organize to lower transaction costs and solve coordination problems at the local level.

\subsection{Externalities and a benign dictator}

One way to overcome the coordination and pricing issue of externalities is to assume a benign and well informed dictator who controls the whole municipality. This dictator seeks to maximize social welfare for the municipality as a whole. Any externality will then be internalized. Moreover, the dictator is well informed about the internal demand in the municipality and demand from non-residents. Hence, the dictator allocates resources so that a Pareto-optimum is reached from the perspective of the municipality.

\subsection{Coordination among independent agents}

The benign dictator is a theoretical construction. Nobody possesses perfect information about the preferences of all people in a (local) community, but as a yardstick the dictator allocation is interesting. A central question is how we can replicate the resource allocation of the benign and well informed dictator.

In the absence of externalities, complete and perfect markets we know that a Walrasian exchange economy also will result in a Pareto-optimal allocation (for an overview see Varian 1992). In our setting these requirements are unlikely to be met. This is the case if some of the goods demanded public, i.e., they are non-rival and non-exclusive in consumption (Randall 1982). Landscape amenities ${ }^{5}$ like scenic beauty or habitat for wildlife are examples of such goods. From the only peer reviewed published study we found (Getz and Brown 2004, on wine tourism) we know that landscape amenities are important when some tourists choose where to go on vacation. A Walrasian exchange economy ${ }^{6}$ is therefore unlikely to produce a resource allocation that will result in social welfare maximization.

Seabright (1993) presents an overview of the incentive issues related to local commons. Here, we limit our exposition to discussing three main approaches. The first (and obvious) solution in the case of providing positive externalities is to have those benefiting from the supply of a non-market good pay for it through some contractual arrangement.
Flat rate payments, where any supplier who accepts the contract terms is compensated. One problem with this approach is that it may result in over- or under-supply as the buyer does not know the costs of providing the good in question. Consequently, the buyer cannot know if the contracts have been allocated to the least cost providers if the buyers' budget is exceeded.

Auctions constitute another way of having such contracts allocated to the least cost providers. Usually, multiple contracts will be allocated. This renders ordinary auctions of little use as they are prone to strategic bidding. To see this, consider that each provider is paid according to his or her bid. A potential provider who is reasonably certain he is of the low cost may gain from raising his bid somewhat. Then the bids will not represent the true costs of meeting contract terms, and contracts may be allocated to the least cost providers (Romstad 2009). Some concerns have been raised related to the ability of decentralized decision schemes like auctions to achieve spatial coordination (an issue of concern for landscape amenities), but incentives in auctions can be formulated to solve these issues (Parkhurst et al. 2002; Warziniack et al. 2007).

A uniform price auction ${ }^{7}$ does not suffer from the same problems of potential providers not bidding their true costs. Polasky and Romstad (2009) show how such an auction can be designed to allocate forest management contracts for biodiversity conservation purposes. Their approach is also applicable for the allocation of multiple management contracts in other settings, for example if a hotel owner would like parts of an area to be managed to enhance the scenic beauty of the landscape.

A third type of side payments emerge from direct cooperation in what is termed cooperative games. While cooperative game theory may provide an avenue for resolving some coordination issues within municipalities, it suffers from one major problem: The pre-cooperative phase is non cooperative, and that there exists no standard approach of telling what will be the cooperative outcome, if any (Gibbons 1997). ${ }^{8}$ Moreover, we know at the municipality level there already exists various forms of cooperation

At this stage, however, we return to the perspectives of Ostrom (1990, 1995), which brings us to networks, self organization, and social and human capital.

\section{Social and human capital: benefits and liabilities of social networks}

Social capital is defined as the potential resources embedded in a social network that can be mobilized to facilitate actions (Adler and Kwon 2002). Social capital has

\footnotetext{
4 Other accessible works by Ostrom and coauthors on these issues include Ostrom and Gardner (1993) and Dietz, Ostrom and Stern (2003).

5 Randall (2002) discusses the challenges of valuing landscape amenities.

6 Some times the term the Walrasian auctioneer is used (see for example Kranton and Minehart 2001).

7 Uniform price auctions are a variation of Vickrey's (1961) second price auction.

8 See also Romstad (2005) for an accessible overview on these issues.
} 
shown to represent benefits for a focal actor as a member of the network, such as firm start-up success (Gordon et al. 1997), and also for the network as a whole, e.g. through facilitating cost-effective transfer of complex information and tacit knowledge (Hansen 1999). Basically, the sources of social capital are the actors in the network (the human capital) and the relationships between them (defined as ties). The motivation for network participation stems from the potential resources the network represents for the focal actor. These resources - the social capital - are categorized into three main groups: information, influence and solidarity (Adler and Kwon 2002).

A major issue within social capital research has been to investigate the structural form of different types of networks and how these affect the size or strength of social capital embedded within it (Gabbay and Leenders 2001). Knowledge on what types of networks that produce the largest social capital will enable economic actors to carefully build and sustain optimal networks for their specific resource needs. There are two main views in the literature on what kinds of networks structures that produces most social capital (Gabbay and Leenders, ibid.; Gargiulo and Benassi 2000). One is the closure argument, predicting that dense networks with strong ties and a high degree of interconnectedness to a larger degree will produce social capital in the form of trust, norms of cooperation, which mobilizes collective action. The other view is that large networks of weak ties, with many "structural holes" represents more social capital for the actors, specifically for actors who are in the position to bridge structural holes of information (Burt 2001).

Several scholars have however pointed to the fact that networks not only produce benefits for the actors, but are also associated with costs, risks and social liabilities (Hansen et al. 2001; Portes 1998). For example, Hansen and colleagues (1999) found that some teams with many external ties used too much time to maintain these ties and hence performed their tasks slower. Portes points to the fact that mobilizing other network contacts to provide help, support or information may be costly, and that institutionalized networks have norms of reciprocation, so some actors may have large "social depth", which restrains behavior and induces costs (Portes 1998; Ladegard 2006).

Introducing a task contingency perspective, Hansen and colleagues (Hansen et al. 1999) argue that the benefits of different types of ties and network structures depend on the task at hand. Studying information and knowledge transfer, they found that teams that performed product development tasks (defined as knowledge exploration tasks), needed rich and diverse information and hence benefited more from a large external network. For teams with knowledge exploitation tasks, however, specific and non-redundant rather than diverse knowledge is needed and the costs of a large external network outweighed the benefits. This study shows how networks may represent different social capital for different tasks, and hence provides knowledge on how a local group of producers may use networks to pursue marked needs.
Taking the Hansen family example again, the different needs of the family members require cooperation, coordination and seamless "packages" of services to the family, that we denote the coordination tasks. These tasks require trust, collaborative norms, and low transaction costs between the producers, and thus points to a dense network with strong ties. This kind of network produces strong goodwill, and hence social capital benefits for the individual actors, as well as low transaction costs.

However, the whole idea of providing services and products to a market requires some sort of "exploration tasks", i.e., product and service development, innovation, and continuous market adjustment. These kinds of tasks require diverse and rapid development of new knowledge, and rich external information from markets and potential customers. Therefore, the exploration tasks call for a large network with weak ties and rich in structural holes, to be able to span a large amount of information, diverse information and market changes. This kind of network structure provides the actors with social capital in the form of novel and relevant market information, as well as innovative opportunities.

Similar, but opposite arguments can be formed for the costs or liabilities of the two types of network structures. A small network with strong ties has a high degree of closure, and little external information is channeled into the actors in the network. Thus, this network will represent liabilities for each actor towards the other actors, and may hamper individual actors' attempts to pursue product development or other individual changes in products and services. Further, a network with high closure is propounded to ignore external information, and therefore become production rather than market oriented. As the strong ties and mutual liabilities between the actors also restrain individual deviant behavior, this kind of network may probably have difficulties to respond to market demands as time passes.

The large and diverse network with many external ties, however, will represent costs in the form of time spent to maintain these relationships, time that is taking attention away from the core business. The time factor may also force actors to allocate less attention to the other producers in the internal network and may result in opportunism and larger coordination costs between the producers. Moreover, the allocation of large resources to shifting market needs may lead to ad-hoc adjustments, reduce focus on long term strategies, and also a loss of focus on identity and the distinctive character of the local products and services.

Therefore, the pursuit of benefits from human and social capital in local network of producers requires careful considerations of the benefits as well as liabilities of different network structures. The benefits and liabilities discussed above are summarized in Table 1 .

Table 1 shows the main factors to consider when building local networks of producers. The importance of the different parameters will differ according to the nature of the products/services as well as the market. Some product/service packages are for example heavily tradition bound, and innovation efforts must always take into account 
Table 1: Social capital and social liabilities of different network structures

\begin{tabular}{|c|c|c|}
\hline & $\begin{array}{l}\text { Dense network, strong ties, } \\
\text { high degree of closure }\end{array}$ & $\begin{array}{l}\text { Large network with weak ties and } \\
\text { structural holes }\end{array}$ \\
\hline Benefits & $\begin{array}{l}\text { Coordination benefits: } \\
1 \text { Seamless packages of services } \\
\text { and products } \\
2 \text { Reduced transaction costs } \\
\text { Goodwill benefits: } \\
3 \text { Governed by shared norms, } \\
\text { less control needed } \\
4 \text { Help, support and solidarity }\end{array}$ & $\begin{array}{l}\text { Knowledge benefits: } \\
5 \text { Responsivity to market needs } \\
6 \text { Knowledge about new products, } \\
\text { services, competitors } \\
\text { Innovation benefits: } \\
7 \text { Diverse information from many } \\
\text { sources } \\
8 \text { Individual initiatives drives } \\
\text { development }\end{array}$ \\
\hline $\begin{array}{l}\text { Costs and } \\
\text { liabilities }\end{array}$ & $\begin{array}{l}\text { Narrow focus on production } \\
9 \text { Irresponsive to market needs } \\
\text { 10Ignorance about competitors } \\
\text { Strong collective norms } \\
\text { 11 Restraint on individual behavior } \\
\text { 12Liabilities in the form of } \\
\text { reciprocation of favors and help }\end{array}$ & $\begin{array}{l}\text { External focus } \\
\text { 13 Loss of identity } \\
\text { 14 Time allocated away from core } \\
\text { activities } \\
\text { Lack of coordination } \\
\text { 15 Individual initiatives may undermine } \\
\text { the collective packages } \\
\text { 16 Increased opportunism } \\
\text { and transaction costs }\end{array}$ \\
\hline
\end{tabular}

the common weak knowledge about markets and customers in (rural) municipalities:

(1) to acquire social and human capital from external sources, for example by hiring external consultants, or

(2) to reallocate more time to the network activities at the expense of the remaining time allotted to running the business or reduced leisure.

The second option clearly has its disadvantages, both related to family and own well-being, and because restructuring a business to be more demand oriented is by itself time consuming.

\section{Concluding remarks}

We firmly believe that creating value added is a corner stone of any successful rural the effects on the local identity of the products and services. If this is the case, it will be important to form networks with strong ties to at least some actors with extensive local knowledge, to secure goodwill from these sources.

Participation in networks requires time, which is a scarce resource. Forming well founded expectations about the benefits of participating in the two network types are important to be able to allocate (the scarce) time in an appropriate way. These matters are not made easier by the fact that coordination networks often require some minimum commitment for the network to serve its coordinative purpose. Figure 4 illustrates this schism, which here leads to a loss of value (the yellow area) because of other network participants' expectations about time committed to the network.

Optimal allocation of the total time takes place where the marginal value of time participating in the coordination network equals marginal value of time participating in the innovation network. Figure 4 depicts what we perceive to be a frequent occurrence - value gains are to be made by reallocating time from the coordination to the innovative network. If this is difficult, there are two ways to overcome

development strategy. This implies being able know who are the relevant consumer segments and their preferences. Understanding the demand side is imperative to being able to redirect the supply side so that what is produced actually can be sold, preferably at as high prices as possible. It is our impression (not having worked much in rural development ourselves) that the demand side has been given too little attention in rural development, both in terms of (public) rural development strategies, and in the rural development literature.

A stronger demand focus requires going outside the local municipality. Increased emphasis therefore needs to be placed on information processing and innovation. Networks play an important role in terms of lowering the costs of these activities. Such networks are usually large differ with weak ties and structures (Table 1). These attributes make explorative and innovation networks substantially from coordination networks that are characterized by strong ties and mutual commitments.

The allocative challenges are substantial for firms producing multiple products. These challenges grow manifold at the municipality level because of the increased dimensions of the production possibility set and because of externalities (spillovers) between enterprises. Coordination networks are needed to help solve these allocative issues at the municipality level. However, care must be taken so that these networks, that are closed and often inward looking, do not prevent the highly needed work to be done on mapping and understanding the demand side.

As mentioned in our introduction there has been little done on matching the demand and supply side related to rural and regional development. This is an area where more research is needed, and where the benefits to practical rural and regional development are likely to be large. We have also seen that there is a potential dichotomy between coordination

Figure 4: Time allocation between coordination and innovation networks. 
networks and explorative and innovation networks. Because the coordination networks require a minimum commitment of time, it is difficult to reduce the time allotted to these networks. Making coordination networks more outward looking is one way to resolve the time conflict between the two network types. A key question is then how to make the coordination networks more outward looking while maintaining their allocative role in municipalities.

\section{References}

Adler, P. S., \& S.W. Kwon (2002): Social capital: Prospects for a new concept. Academy of Management Review, 27(1), 17-40.

Baumol, W.J. \& W.E. Oates (1988): The theory of environmental policy. 2nd. Edition. Cambridge University Press, Cambridge, MA.

Burt, R. S. (2001): Structural Holes versus Network Closure as Social Capital. In N. Lin, K. Cook \& R. S. Burt (Eds.), Social Capital. Theory and Research (pp. 31-56). Aldine de Gruyter Inc., New York, NY.

Chambers, R.G. (1988): Applied Production Analysis: A Dual Approach. Cambridge University Press, New York, NY.

Debertin, D.L. (1986): Agricultural Production Economics. Macmillan Publishing Company, New York, NY.

Dietz, T., E. Ostrom, \& P.C. Stern (2003): The Struggle to Govern the Commons. Science, 302 (5652): 1907-1912. DOI: 10.1126/science. 1091015 .

Gabbay, S. M., \& Leenders, R. T. A. J. (2001): Social Capital of Organizations: From Social Structure to the Management of Corporate Social Capital. In S. M. Gabbay \& R. T. A. J. Leenders (eds.), Social Capital of Organizations (Vol. 18, pp. 1-20). Elsevier, Oxford, UK.

Gargiulo, M.\& M. Benassi (2000): Trapped in your own net? Network cohesion structural holes, and the adaptation of social capital. Organization Science, 11 (2): 183-196.

Getz, D. \& G. Brown (2004): Critical success factors for wine tourism regions: a demand analysis. Tourism Management, 27 (1): 146-158. doi:10.1016/j.tourman.2004.08.002.

Gibbons, R. (1997): An Introduction to Applicable Game Theory. Journal of Economic Perspectives, 11 (1): 127-149.

Gordon, W., B. Kogut \& W. Shan (1997): Social Capital, Structural Holes and the Formation of an Industry Network. Organization Science, 8 (2): 109-125.

Hansen, M. T. (1999): The search-transfer problem: The role of weak ties in sharing knowledge across organization subunits. Administrative Science Quarterly, 44 (1): 82-111.

Hansen, M. T., J.M. Podolny \& J. Pfeffer (2001): So Many Ties, so Little Time: A Task Contingency Perspective on Corporate Social Capital in Organizations. In S. M. Gabbay \& R. T. A. J. Leenders (eds.), Social Capital of Organizations (Vol. 18, pp. 21-57), Elsevier, Oxford, UK.

Johansen, L. (1972): Production Functions, North-Holland Publishing Company, Amsterdam, The Netherlands.

Kranton, R.E. \& D.F. Minehart (2001): A Theory of Buyer-Seller Networks. American Economic Review, 91 (3): 485-508.

Kydd, J. \& A. Dorward (2004): Implications of market and coordination failures for rural development in least developed countries. Journal of International Development, 16 (7): 951-970.
Ladegard, G. (2006): Accessing Social Capital through Conformity: Investigating Network Cultures. In Kornberger, M. \& S. Gudergan (eds.) Only connect: Neat Words, Networks and Identities. Advances in Organization Studies. Liber., Oslo/Copenhagen.

Léon, Y. (2005): Rural development in Europe: a research frontier for agricultural economists. European Review of Agricultural Economics, 32 (3): 301-317. doi:10.1093/eurrag/jbi012.

Ostrom, E. (1990): Governing the commons: The evolution of institutions for collective action. Cambridge University Press, Cambridge, MA.

Ostrom, E. (1995): Self-organization and Social Capital. Industrial and Corporate Change, 4 (1): 131-159.

Ostrom, E. \& R. Gardner (1993): Coping with Asymmetries in the Commons: Self-Governing Irrigation Systems Can Work. Journal of Economic Perspectives, 7 (4): 93-112.

Parkhurst, G.M., J.F. Shogren, C. Bastian, P. Kivi, J. Donner \& R.B.W. Smith (2002): Agglomeration bonus: an incentive mechanism to reunite fragmented habitat for biodiversity conservation. Ecological Economics, 41: 305-328.

Polasky, S. \& E. Romstad (2009): An auction mechanism for optimal conservation under asymmetric information. Manuscript with revise/resubmit to Journal of Environmental Economics and Management.

Portes, A. (1998): Social Capital: Its origins and applications in modern sociology. Annual Review of Sociology, 24 (1): 1-24.

Randall, A. (1983): The problem of market failure. Natural Resources Journal, 23 (1): 131-148.

Randall, A. (2002): Valuing the outputs of multifunctional agriculture. European Review of Agricultural Economics, 29 (3): 289-307.

Romstad, E. (2005): Game Theory and Resource Allocation Mechanisms. Lecture note in ECN 371, Department of Economics \& Resource Management, Norwegian University of Life Sciences, Norway [http://athene.umb.no/emner/pub/ECN371/notes/ram.html accessed September 10, 2009].

Romstad, E. (2008): The Informational Role of Prices. European Review of Agricultural Economics, 35 (3): 263-280. doi:10.1093/ erae/jbn020.

Romstad, E. (2009): Auctions: Theoretical background and empirical applications in natural resources. Presentation at the EAAE workshop "Valuation methods in agro-food and environmental economics - Experimental auctions: theoretical background and empirical applications", CREDA, Barcelona, July 2-3, 2009. [http://www.creda.es/ workshops_002.htm accessed September 11, 2009].

Seabright, P. (1993): Managing Local Commons: Theoretical Issues in Incentive Design. Journal of Economic Perspectives, 7 (4): 113-134.

van Huylenbroeck, G. \& G. Durand (eds.) (2003): Multifunctionality Agriculture: A New Paradigm for European Agriculture and Rural Development (Perspectives on Rural Policy and Planning). Ashgate Publishers, Aldershot, United Kingdom.

Varian, H.R. (1992): Microeconomic Analysis. 3rd edition, Norton, New York, NY.

Vickrey, W. (1961): Counterspeculation, auctions and competitive sealed tenders. Journal of Finance, 16 (1): 8-37.

Warziniack, T., J.F. Shogren \& G.M. Parkhurst (2007): Creating contiguous forest habitat: an experimental examination on incentives and communication. Journal of Forest Economics, 13 (2-3): 191-207 